\title{
FIUCOME 2009
}

10th International Conference on Fluid Control, Measurements, and Visualization August 17-21, 2009, Moscow, Russia

\section{VISUALIZATION OF FLOW FIELD OF HIGH-SPEED PULSATING JET BY MACH-ZEHNDER INTERFEROMETRY}

\author{
Nobuhiko Sato ${ }^{1}$ and Junjiro Iwamoto ${ }^{2}$
}

\begin{abstract}
The high-speed pulsating flow is found in the exhaust system of the reciprocating internal combustion engine, the piping system connected to reciprocating compressor, etc., and has various features which never exist in steady flow. This work is concerned with an experimental study of the high-speed pulsating jet discharged by straight pipe. The pulsation is generated by disk-type rotary valve at upstream end of the pipe, and frequency of pulsation can be varied by changing the rotating speed of the valve. The flow field is visualized by Schlieren photography and Mach-Zehnder interferometry for different pressure ratios of plenum chamber to atmosphere at different speeds of the rotary valve.
\end{abstract}

\section{Keywords: Pulsating Flow, Compressible Flow, Flow Visualization, Shock Wave, Vortex ring}

\section{INTRODUCTION}

The pulsating flow is found in a pipe connected to a reciprocating pump with periodic pressure fluctuation, in blood vessel, etc. When the flow velocity is as high as the speed of sound or higher and the range of pressure fluctuation is large, it is called a high-speed pulsating flow. Such flow is found in the exhaust system of the reciprocating internal combustion engine, in the piping system connected to reciprocating compressor, etc. When the high-speed pulsating flow is generated in these pipes, compression wave and expansion wave are formed, making flow phenomenon complicated. In addition, compression wave can grow into a shock wave. When the pulsating flow with the shock wave is issued from the pipe end, very big noise is produced.

In this experimental study, the high-speed pulsating flow is generated by disc-type rotary valve and it passes through the straight pipe, which simulates the flow in the exhaust pipe of the reciprocating internal combustion engine.

\footnotetext{
${ }^{1}$ Corresponding author: Student, Graduate School of Engineering, Tokyo Denki University, Chiyoda-ku, Tokyo 101-8457, Japan. e-mail: 08gmm11@ms.dendai.ac.jp

${ }^{2}$ Professor, Department of Mechanical Engineering, Tokyo Denki University, Chiyoda-ku, Tokyo 101-8457, Japan.
} 


\section{EXPERIMENTAL APPARATUS}

\section{Piping System and Rotary Valve}

Figure 1 shows the experimental arrangement. Compressed air from two compressors passes through an air-dryer, surge tank, and two oil-mist separators, and is steadily supplied into plenum chamber. The pressure in the plenum chamber $p_{0}$ can be adjusted by controlling the air release valves. The air goes through the rotary valve which is fitted to the plenum chamber and which generates the flow pulsation, and flows into the straight pipe of $1000 \mathrm{~mm}$ in length. And then, the air is discharged into sound proof room under atmospheric condition.

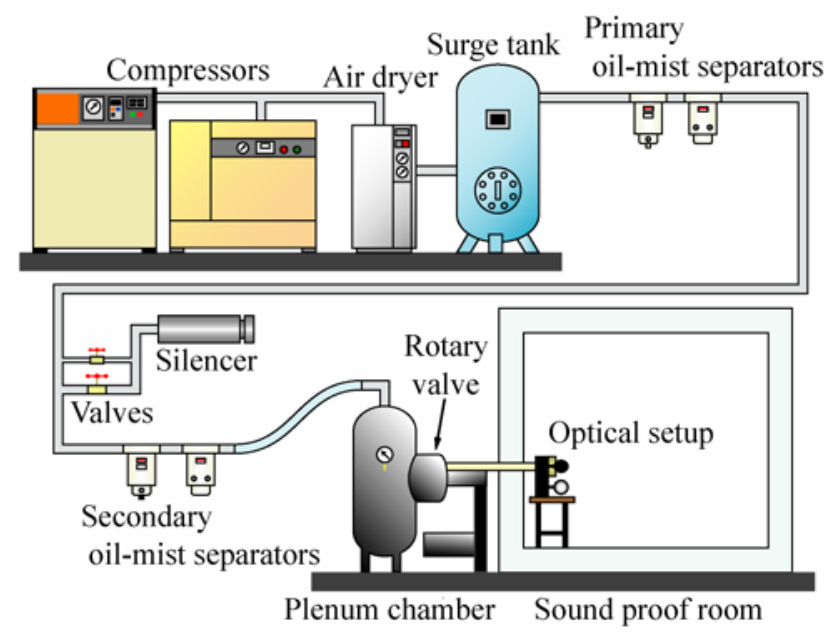

Fig. 1. Schematic of experimental arrangement

Figure 2 shows the disc-type rotary valve installed on plenum chamber. The flow characteristics of the rotary valve has been studied very much and well known (Iwamoto, 1974). This valve has a circular disc with two holes inside the casing. By rotating the disc the opening area through which the air passes into the straight pipe is varied, and the high-speed pulsating flow is generated in the pipe. The pressure ratio of plenum chamber to atmosphere $P R=p_{0} / p_{\text {atm }}$ is varied from 1.50 to 4.00 and the rotating speed of rotary valve $n$ from 1000 to $4000 \mathrm{rpm}$.
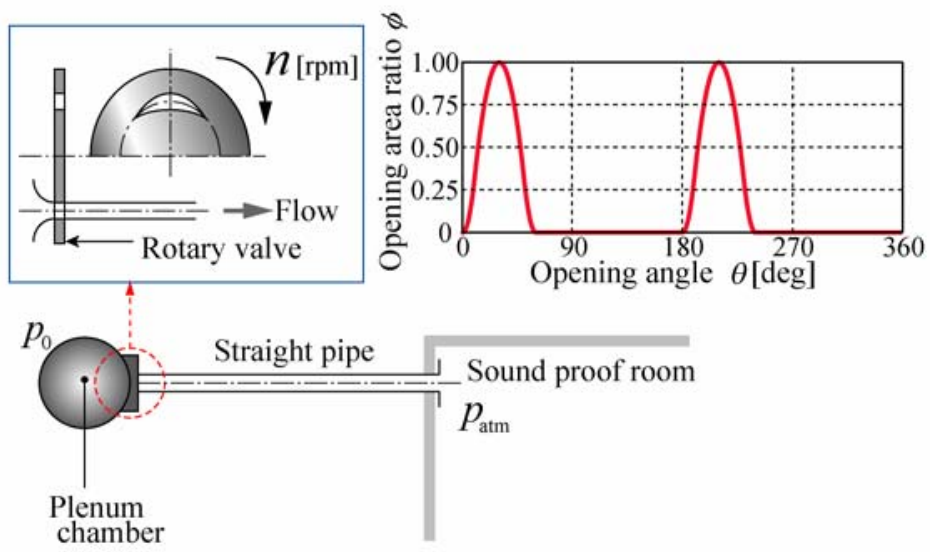

Fig. 2. Schematic of rotary valve 


\section{Optical System}

Figure 3 shows the Mach-Zehnder interferometry setup. Laser diode which has output $35 \mathrm{~mW}$ and wavelength $650 \mathrm{~nm}$ is employed as light source. The timing of light emission is controlled by output waveform from function generator, its duration being $4 \mu \mathrm{sec}$. The light which is diffused and is made parallel is divided into two rays, and joined again after one of them passes through the test section. The light ray makes fringe pattern on digital camera at imaging point after convergence.

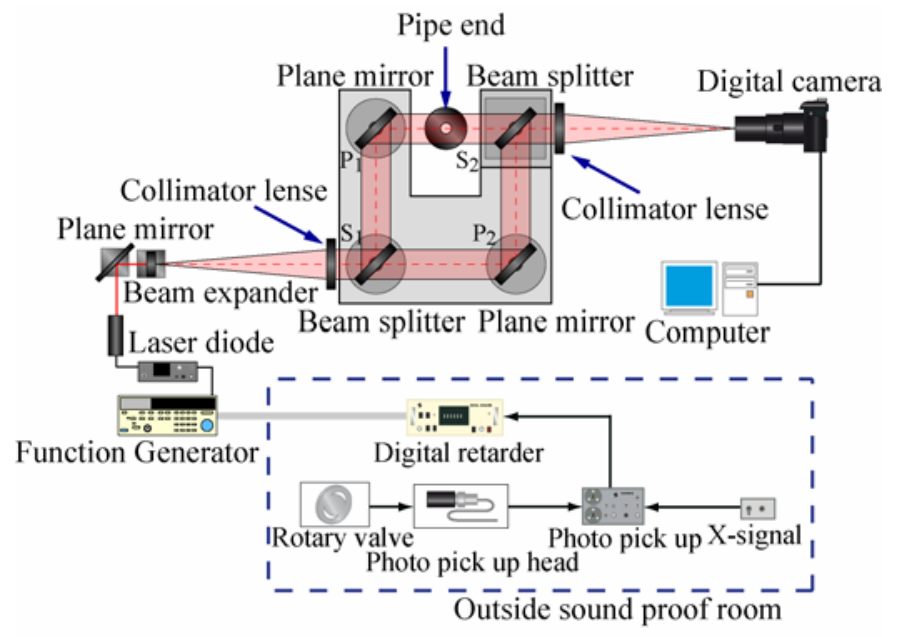

Fig. 3. Schematic of Mach-Zehnder interferometry setup

In Schlieren photography Xenon discharge tube is employed as light source, whose light emission is triggered by the signal generated at the moment when the rotary valve starts to open. The light ray passes through the condenser lens and the pin hole into concave mirror where it is reflected as parallel ray. The ray after passing through the test section is reflected from the concave mirror, and is converged. The knife edge is placed at the focus, behind which the digital camera is set.

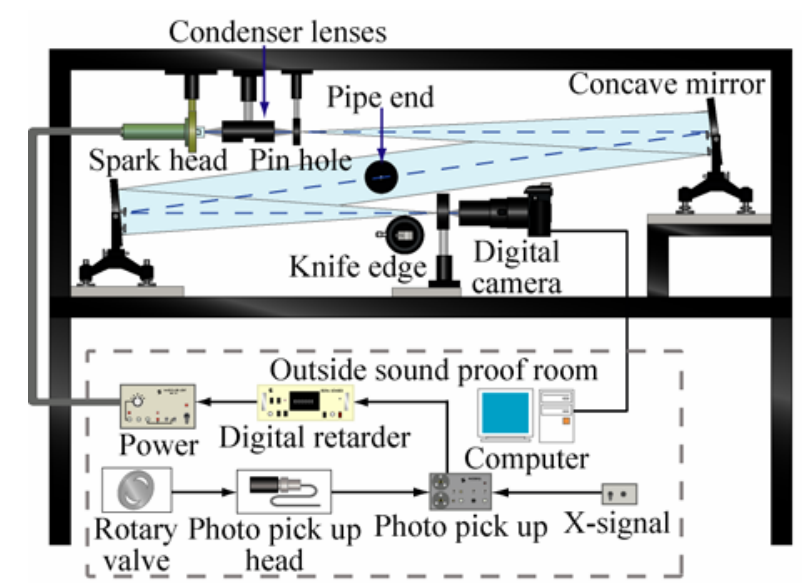

Fig. 4. Schematic of Schlieren method 


\section{RESULTS AND DISCUSSION}

\section{Visualization of Flow Field}

Figure 5 shows a sequence of visualized flow fields at nozzle pressure ratio $P R=4.0$ and at $n=4000$ $\mathrm{rpm}$, where the abscissa is non-dimensional distance $x / D(x$ is the distance measured from the pipe end and $D$ the pipe diameter) and the ordinate the non-dimensional radial distance $y / D$. Since the flow field is axisymmetric, the upper half shows Schlieren picture and the lower half density distribution obtained from the Mach-Zehnder interferometry in each figure. Time $t$ is non-dimensionalized by $\tau$, a period of pulsation.

When the rotary valve opens at the upstream end of the pipe, compression wave is produced and is followed by expansion wave generated during the closure of the valve. As the compression wave propagates through the pipe, it can grow into a shock wave.

Table 1 exhibits the conditions for the shock wave to appear from the tube. Note that at pressure ratio as low as 1.5 , shock wave appears when the rotary valve speed is high.

Figure 5(a) shows the flow pattern at $t / \tau=0.321$, where the shock wave is discharged from the pipe end and becomes spherical as it propagates downstream, the density being high behind the shock. Upstream of the shock there remains subsonic jet which is generated at the previous cycle and for this reason the spherical shock weakens more as it propagates than it does in still air. Due to the velocity difference between the jet and ambient air the jet boundary is rolled up to form a vortex ring as can be seen near the pipe exit. At $t / \tau=0.324$, the spherical shock moves further downstream and the vortex ring grows as seen in Fig. 5(b). Especially, the vortex core can easily be identified as its density is the lowest in the field.

As the vortex ring propagates downstream, vortex sheet around vortex core expands as shown in Fig. 5(c). It is thought that suction works at vortex core in addition to aforementioned shearing action by velocity difference. Thus, flow passage of jet flowing into the vortex ring is narrowed, giving rise to the similar effect caused by the converging-diverging nozzle and resulting in the formation of another shock inside the vortex ring (Kimura and Iwamoto, 2002; Minota, 1998). This is rearward-facing shock (Endo and Iwamoto, 2005). As time elapses, the vortex core expands slightly into radial direction. Then, as shown in Fig. 5(d) underexpanded jet forms and follows the shock in the vortex ring.

Table 1. Appearance of spherical shock wave

\begin{tabular}{c|c|c|c|c|c|c}
\hline \hline \multirow{2}{*}{$\begin{array}{c}n \\
\mathrm{rpm}\end{array}$} & \multicolumn{7}{|c}{$P R$} \\
\cline { 2 - 7 } & 1.50 & 2.00 & 2.50 & 3.00 & 3.50 & 4.00 \\
\hline 1500 & - & - & - & - & - & - \\
\hline 2000 & - & - & - & - & $\circ$ & $\circ$ \\
\hline 2500 & - & $\circ$ & $\circ$ & $\circ$ & $\circ$ & $\circ$ \\
\hline 3000 & - & $\circ$ & $\circ$ & $\circ$ & $\circ$ & $\circ$ \\
\hline 3500 & $\circ$ & $\circ$ & $\circ$ & $\circ$ & $\circ$ & $\circ$ \\
\hline 4000 & $\circ$ & $\circ$ & $\circ$ & $\circ$ & $\circ$ & $\circ$ \\
\hline \hline
\end{tabular}




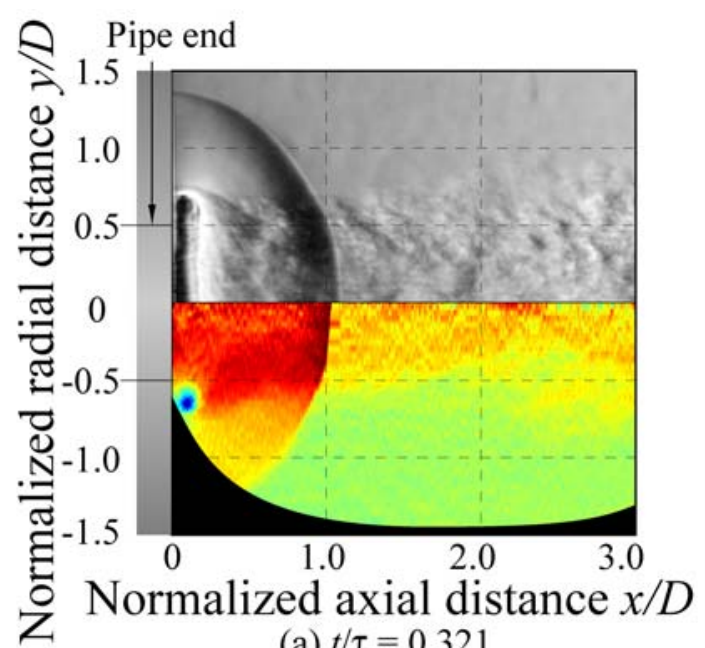

(a) $t / \tau=0.321$

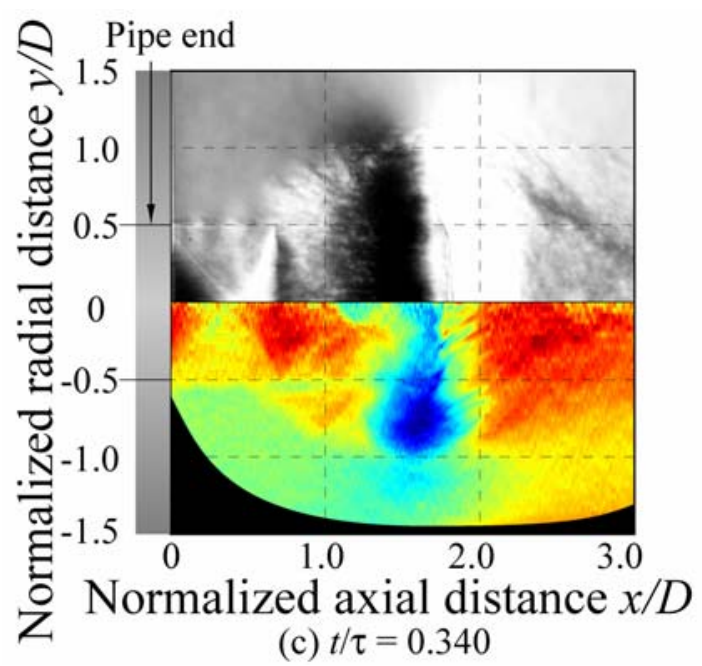

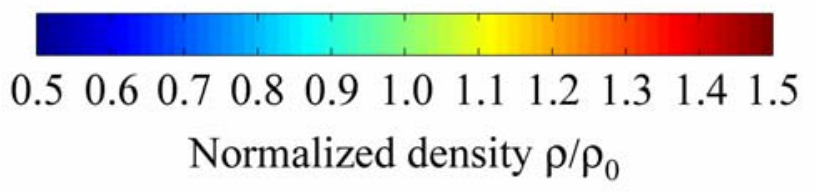

Fig. 5. Schlieren photographs and density distributions at $P R=4.00, n=4000 \mathrm{rpm}$

\section{Shock Wave in Vortex Ring}

Figure 6 shows visualized pictures of the flow field under the conditions shown in the captions. In each figure the upper half shows Schlieren picture, while the lower half is the fringe pattern obtained from Mach-Zehender interferometry.

At $P R=4.0$ the shock wave in vortex ring is seen at $n=3000$ and $4000 \mathrm{rpm}$ in Figs. 6 (a) and 6(b), respectively. Table 2 shows propagation velocities of spherical shock and the vortex ring, and whether the shock appears in vortex ring or not. From Table 2, it is found that the formation of the shock wave in the vortex ring tends to depend on the pressure ratio $P R$ and not on the propagation velocity. 
In the present experiment, capturing the shock in detail by interferometry is difficult. It is thought that the ratio of the area which the shock wave in vortex ring occupies to that of the vortex ring is small so that the shock wave is buried in the vortex ring in the photograph of the interference fringe. Moreover, since light-emitting duration of laser is as long as $4 \mu \mathrm{s}$, it is considered that it could not capture minute fluctuation of flow field such as the shock wave in the vortex ring.

Table 2. Velocity of vortex ring and shock wave

\begin{tabular}{|c|c|c|c|c|}
\hline \multirow{2}{*}{$P R$} & \multirow{2}{*}{$\begin{array}{c}n \\
\mathrm{rpm}\end{array}$} & \multicolumn{2}{|c|}{ Propagation velocity m/s } & \multirow{2}{*}{$\begin{array}{l}\text { Shock wave } \\
\text { in vortex ring }\end{array}$} \\
\hline & & Spherical shock wave & Vortex ring & \\
\hline \multirow{2}{*}{3.00} & 3000 & 357.9 & 139.8 & - \\
\hline & 4000 & 404.3 & 168.2 & - \\
\hline \multirow{2}{*}{4.00} & 3000 & 396.3 & 167.3 & 0 \\
\hline & 4000 & 452.5 & 195.5 & ○ \\
\hline
\end{tabular}

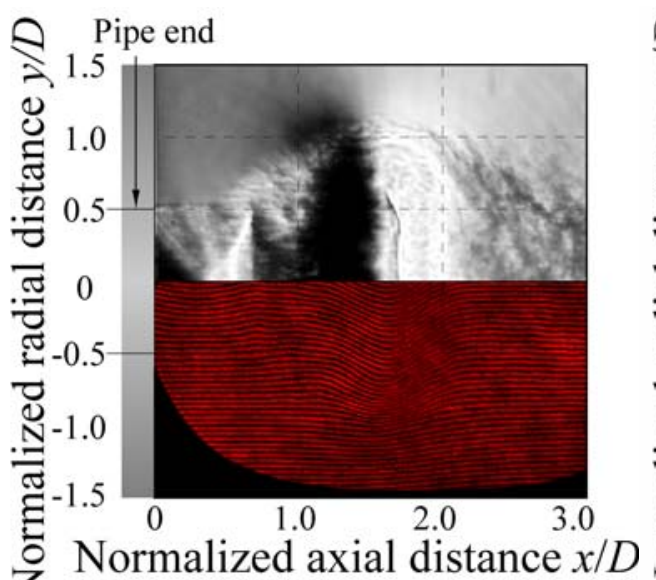

(a) $P R=4.00, n=4000 \mathrm{rpm}$ $t / \tau=0.340$

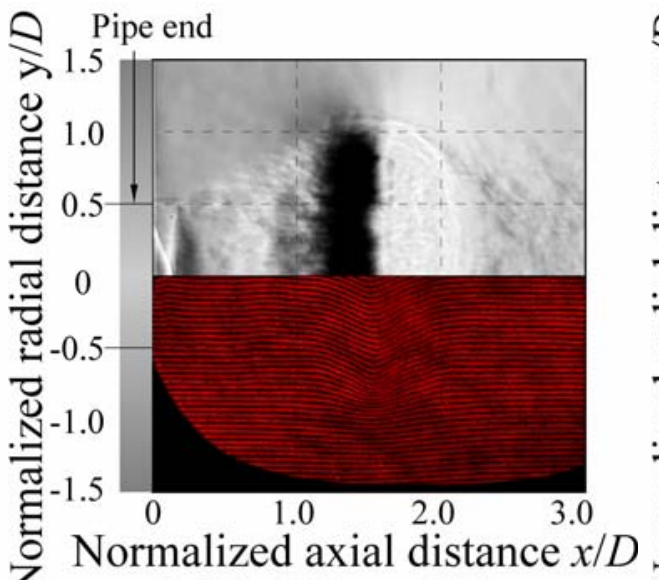

(c) $P R=3.00, n=4000 \mathrm{rpm}$ $t / \tau=0.361$

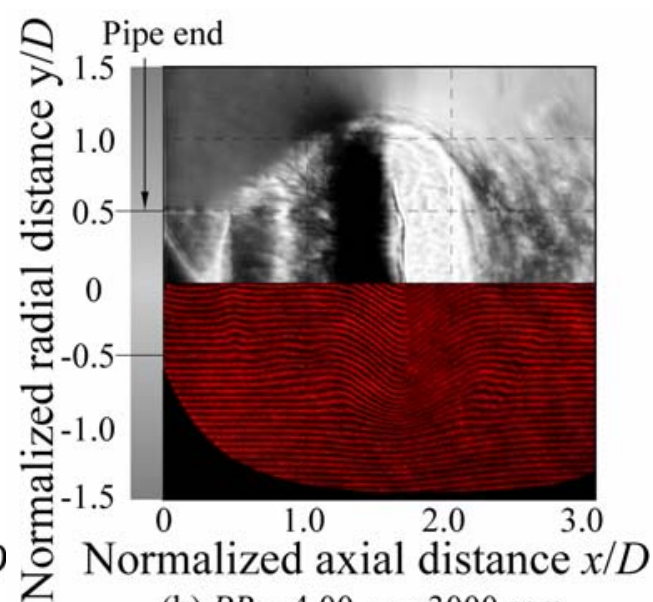

(b) $P R=4.00, n=3000 \mathrm{rpm}$ $t / \tau=0.274$

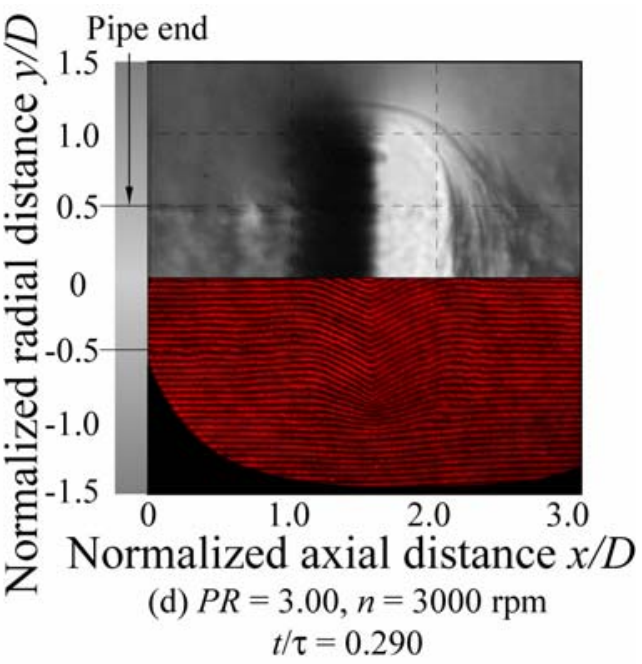

Fig. 6. Schlieren photographs and fringe pattern photographs 


\section{CONCLUSIONS}

Using flow visualization, high-speed pulsating flow at different pressure ratios and different speeds of rotary valve is investigated, and the following conclusions are derived.

1. Attenuation of spherical shock wave occurs faster at higher pressure ratios. The density decrease in the vortex ring is much more at higher pressure ratios.

2. The vortex ring is formed under all experimental conditions, its size being dependent upon pressure ratio $P R$. But the expansion of the vortex core to radial direction is almost constant, irrespective of experimental conditions.

3. Even at $P R=1.50$, shock wave is formed in the pipe and discharged at $n=3500 \mathrm{rpm}$ and $4000 \mathrm{rpm}$. At $n=1500 \mathrm{rpm}$, shock does not form even when $P R=4.00$.

\section{ACKNOWLEDGMENTS}

The authors would like to acknowledge the support of Mr. Y. Obuchi. The experiments described above were made in cooperation with Messes. Y. Akagi and J. Motegi. The authors would like to thank their assistances.

\section{REFERENCES}

Iwamoto, J. (1974), "Experimental Investigation of a Rotary Valve", Research Reports of the Faculty of Engineering Tokyo Denki University, 22, 127-150.

Kimura, A. and Iwamoto, J. (2002), "Journal of Visualization”, 5(4), 371-379.

Minota, T., (1998), "Shock/vortex interaction in a flow field behind a shock wave emitted from a shock-tube", Proc. of 2nd Int. Workshop on Shock-Wave/Vortex Interaction, (1998), 2-11.

Endo, M. and Iwamoto, J. (2005), "A Study on Shock Wave formed in Unsteady Jet through Vortex Ring", Transactions of JSME (B), 71(712), 2928-2933 (in Japanese).

\section{APPENDIX I. NOTATION}

D Diameter of straight pipe [mm]

$n \quad$ The rotating speed of rotary valve $[\mathrm{rpm}]$

$p_{0} \quad$ Pressure of plenum chamber [atm]

$p_{\text {atm }} \quad$ Atmospheric pressure [atm]

$P R \quad$ Pressure ratio of plenum chamber to atmosphere

$\rho \quad$ Density $\left[\mathrm{kg} / \mathrm{m}^{3}\right]$

$\rho_{0} \quad$ Density of plenum chamber $\left[\mathrm{kg} / \mathrm{m}^{3}\right]$

$t \quad$ Elapsed time from the moment when the rotary valve opens [msec]

$\tau \quad$ Time of one cycle of pulsation [msec] 